\title{
The Clayton Memorial Lecture, 1978: "Is Immunoprophylaxis in Leprosy Feasible?"
}

\author{
TORE GODAL \\ Laboratory for Immunology, Department of Pathology, \\ Norsk Hydro's Institute for Cancer Research, \\ The Norwegian Radium Hospital, Montebello, Oslo 3, Norway
}

Mr Chairman, Ladies and Gentlemen,

Before I reveal my incompetence in the subject to be discussed, I should like to thank Lepra with its Director, Francis Harris and the Chairman of the Medical Advisory Board, Dr Rees, for the invitation to give this year's Clayton Memorial Lecture.

As you all know, the World Health Organization, over the last years, has increasingly focused its attention on the health of the poorest billion in the world. By the slogans "Health by the people" and "Health for all by year 2000 " the principle of "self-reliance" is promoted at all levels. This also applies to medical research.

It has been estimated that only $1 \%$ of the total global biomedical research effort is being devoted to diseases from which two-thirds of the world population are suffering.

In order to correct this very unsatisfactory situation and stimulate selfreliance, a special programme for research and training in tropical diseases has been established by the World Health Organization.

However, it has been realized that in the field of biomedical research, a considerable period of time is needed to reach self-reliance. The programme has therefore two components, one concerned with institution strengthening in developing countries, and another with research by which expertise anywhere in the world is recruited into the field of tropical diseases.

The research component, organized into scientific working groups (SWGs), is goal-orientated with the objective of developing new methods, such as drugs or vaccines, or simplified methods, for use in the control in tropical diseases. Initially six diseases have been selected: malaria, schistosomiasis, filariasis, trypanosomiasis, leishmaniasis and leprosy. 
The courageous attitude of WHO, by making such an ambitious goal as a leprosy vaccine as target for a research programme, has provoked an open and continuous discussion on all aspects of the targets, including both the feasibility of reaching them and their desirability in the context of disease control.

This year's Clayton Memorial Lecture should be viewed as a part of this ongoing discussion. Thus, if any one of you can put a convincing argument against the development and use of a leprosy vaccine in the context of leprosy control, both considerable human and other resources could be saved.

The discussion may be divided into two parts:

(1) The continuous discussion of problem areas with regard to leprosy control.

(2) The achievements made so far in the Immunology of Leprosy Scientific Working Group (IMMLEP).

In so doing, I shall adopt the health administrator's approach, i.e. start with the size of the health problem and end up with technical, basic immunological questions.

\section{(A) The Size of the Problem}

Leprosy is a chronic infectious disease caused by an acid-fast bacillus (Mycobacterium leprae). Among diseases caused by acid-fast bacilli (or mycobacteria), tuberculosis still represents the greatest health problem. Leprosy comes second to tuberculosis and is estimated to affect between 10 and 15 million people in the world today. The patients are found in the tropical and sub-tropical belt, especially in developing countries. Climatic factors per se, however, are unlikely to have a significant impact on the disease, since several thousand cases were registered in Norway in 1860, with cases as far north as the Lofoten islands beyond the polar circle.

In hyperendemic areas, the annual incidence of leprosy may reach 4-6 per thousand, and the prevalence of the disease frequently exceeds 10 per thousand in Africa and some parts of Asia. In comparison with several other infectious diseases, these figures are not high. Moreover, leprosy is rarely directly, at least - a cause of death. On the other hand, $20-30 \%$ of the patients develop severe forms of deformity. These could amount to several hundred thousand patients per year, but certainly less than 1 million per year.

Thus, in terms of the recent trend to use economic impact as a measure of quantifying a disease problem (e.g. Card and Mooney, 1977) leprosy does not appear a major health problem in any part of the world. Nevertheless, many developing countries rank leprosy among their major health problems (Sansarricq and Walter, 1976).

Therefore, leprosy represents a challenging problem with regard to priority ranking between different diseases. How is one to weigh economic impact against social ostracism? Who should quantitate health problems — the people concerned or health economists?

These problems are heavily influenced by a society's basic view on health. In this decade, especially in relation to aid, health has been judged in an economic 
context. However, evaluation of disease in monetary terms is not easy. For example, the monetary value inferred from several public policy decisions ranges from $£ 50$ (minimum) to $£ 20,000,000$ (maximum) (Card and Mooney, 1977). Moreover, at present basic health needs increasingly appear to be judged in the context of human rights.

\section{(B) Present Methods of Leprosy Control}

Two basic principles of leprosy control are :

(1) early detection of cases, and

(2) treatment to cure or arrest the disease.

Both principles are hampered by a number of problems:

\section{(a) EARLY CASE DETECTION}

Although close contacts of lepromatous patients are at higher risk of developing leprosy than non-contacts, the great majority of patients are found among non-contacts. Thus, surveys cannot be limited to any identifiable high risk group.

The social stigma of leprosy puts pressure on patients to abstain from seeking medical assistance until the disease is advanced and easily recognizable. Because of the stigma, integration of leprosy into general health services is problematic, other patients may protest against being treated in the same place as a "leper", and overextended primary health care systems will have to make tough decisions on priorities.

\section{(b) TREATMENT}

Dapsone remains the major first-line drug in leprosy. It has been used for more than 30 years, is generally well tolerated with few side-effects, and it is inexpensive, costing only a few dollars per year per case.

However, it has a slow action; lepromatous patients remain bacteriologically positive for several years, and acute reactions may occur in patients on treatment. Case holding is therefore a significant problem. In addition, after 30 years of monotherapy, an alarming increase in DDSresistant bacilli has been reported from various parts of the world (see Leprosy Review, 1977). This world epidemic is still apparently only in its beginning.

Combined chemotherapy is now recommended for multibacillary leprosy (World Health Organization, 1977a). However, even when applying combinations which include rifampicin, a most potent antileprosy drug, viable bacilli (so called "persisters") may be detected in patients after 4-5 years of treatment (Waters et al., 1978). Thus cures after short-term treatment regimens do not seem in sight at present.

\section{(c) LEPROSY AND SOCIO-ECONOMIC DEVELOPMENT}

Leprosy declined rapidly in Norway during the period from 1870 onwards (Hansen and Looft, 1895). This decline is generally assumed to be due to 
TABLE 1

Selected comparisons of GNP, health parameters and birth rates*

\begin{tabular}{lccccc}
\hline & $\begin{array}{c}\text { GNP } \\
\text { per } \\
\text { capita }\end{array}$ & $\begin{array}{c}\text { Life } \\
\text { expectancy } \\
\text { years }\end{array}$ & $\begin{array}{c}\text { Death } \\
\text { rate per } \\
1000\end{array}$ & $\begin{array}{c}\text { Infant } \\
\text { mortality } \\
\text { per } 1000\end{array}$ & $\begin{array}{c}\text { Birth } \\
\text { rate per } \\
1000\end{array}$ \\
\hline $\begin{array}{l}\text { Low income countries } \\
\text { India }\end{array}$ & $\$ 152$ & 48 & 17 & 134 & 40 \\
Kerala State (India) & $\$ 140$ & 50 & 15 & 139 & 35 \\
Sri Lanka & $\$ 110$ & 61 & 9 & 56 & 30 \\
Taiwan & $\$ 130$ & 68 & 8 & 45 & 28 \\
Iran & $\$ 810$ & 68 & 5 & 26 & 23 \\
U.S.A. & $\$ 1250$ & 51 & 16 & 139 & 45 \\
\hline
\end{tabular}

*Bloom (personal communication).

socio-economic development, but whether any factor associated with socioeconomic development - like nutrition or education - is of special importance or not, remains unknown.

Since socio-economic development in countries where leprosy now is endemic has different patterns, as epidemiological investigation of leprosy in various developing countries could perhaps throw light on this question. In particular it would seem of interest to learn about leprosy in Kerala state, India, and in Sri Lanka, where health care appears to be of high standards, in spite of low gross national product per capita ratios (Table 1).

This, however, remains at present a hypothesis for exploration, which does not alter the fact that there is no evidence of decline in leprosy on a world-wide basis, and that the prospects of controlling leprosy with the presently available methods appear remote. Research into the development of new tools is therefore an urgent matter.

\section{(C) If Developed, is a Vaccine Likely to Have Any Place in a Leprosy Control Programme?}

The most important question in this regard is the cost/effectiveness of a potent vaccine. Costs may be considered at three levels:

(1) Cost of development: The vaccine component of the IMMLEP programme has been estimated to cost £1.5-2.5 million from start to the end of the first field trial. This is less than 25 pence per patient today.

(2) Production costs: These cannot be estimated at present.

(3) Delivery costs: Since the prevalence of leprosy in endemic areas is low, the delivery costs per case protected are likely to be high if isolated leprosy vaccination campaigns on a mass scale were to be undertaken. However, since multiple vaccines (at least six) may be given simultaneously without negative interference, a leprosy vaccine could be incorporated into larger vaccination programmes. 
Here I have merely pointed to some factors, at present largely unknown, which will have to be considered in due course and balanced against the costs of chemotherapy and other forms of treatment on a per case basis. However, in my view a place for a vaccine in leprosy control cannot be ruled out by presently available cost/effectiveness considerations.

\section{(D) Is Immunoprophylaxis, If Applied, Likely to Have Any Impact on the Infectious Reservoir of Leprosy?}

Since man is the only significant source of $M$. leprae, this question first requires a description of the clinical manifestations in leprosy.

\section{(a) CLINICAL MANIFESTATIONS}

The leprosy bacillus is a slowly growing organism with a generation time of 12-13 days (Shepard, 1971). The incubation period of the disease is also long, ranging from 2 or 3 to more than 10 years. Just as with many other infectious diseases, such as tuberculosis and poliomyelitis, leprosy appears to cause disease in only a minority of those who become exposed to the germ (Godal, $1974 a$ ). Most subjects appear to control the infection effectively at a preclinical stage. In those who develop disease, a wide spectrum of clinical manifestations is encountered. They range from a single, often self-healing skin lesion in so-called tuberculoid leprosy to a disseminated, diffusely infiltrated form called lepromatous leprosy. While tuberculoid leprosy patients are

TABLE 2

Some histological and immunological features in lepros $y^{*}$

\begin{tabular}{|c|c|c|c|c|c|c|}
\hline & TT & BT & $\mathrm{BB}$ & BL & LLs & LLp \\
\hline Epithelioid cells & ++ & ++ & ++ & $\pm /-$ & - & - \\
\hline Non-vacuolated giant cells & $++1-$ & $+1-$ & - & - & - & - \\
\hline Histiocytes/foamy macrophages & - & - & - & ++ & ++ & ++ \\
\hline Lymphocytes & $+ \pm /+$ & $+ \pm / \pm$ & \pm & $++/+$ & $+/ \pm$ & $\pm 1-$ \\
\hline Dermal nerve, maximum diameter in $\mu \mathrm{m}$ & 1000 & 400 & 250 & 200 & 200 & 80 \\
\hline Acid-fast bacilli in granuloma & $-1+-$ & $-1+$ & ++ & +++ & +++ & +++ \\
\hline Acid-fast bacilli in nose & - & - & - & +- & ++ & ++ \\
\hline Lepromin (Fernandez) reaction & +++ & $++/-$ & $+1-$ & - & - & - \\
\hline Lepromin (Mitsuda) reaction & +++ & $++/+$ & - & - & - & - \\
\hline $\begin{array}{l}\text { Lymphocyte transformation test } \\
\text { (\% transformation) }\end{array}$ & 15 & 5.7 & 2.0 & 0.4 & 0.3 & 0.2 \\
\hline Leucocyte migration index & 0.76 & 0.84 & 0.89 & 0.92 & 0.92 & 0.96 \\
\hline Antimycobacterial precipitins & - & - & $-1+$ & $-1++$ & ++ & +++ \\
\hline Anti-M. leprae antibodies & $-1+$ & $-1++$ & ++ & +++ & +++ & +++ \\
\hline Immunological stability & ++ & \pm & - & \pm & + & ++ \\
\hline Borderline reactions & - & + & ++ & + & \pm & - \\
\hline Erythema nodosum leprosum & - & - & - & \pm & ++ & ++ \\
\hline Approximate distribution of cases (\%) & 9 & 24 & 8 & 10 & 31 & 18 \\
\hline
\end{tabular}

*From Godal, 1978 (modified from Ridley, 1974). 
negative on bacteriological examination, billions of bacilli may be found per $\mathrm{g}$ tissue of the skin from lepromatous leprosy patients. These two polar types are interlinked by a range of sub-groups comprising borderline leprosy (see Table 2).

Apart from the skin, the bacilli also thrive in other tissues, especially the nerves. This leads directly, or more often indirectly by the patients' immunological attack on the bacilli inside the nerves, to nerve damage (Godal, 1974b). The resulting paralysis and hyposensitivity over the years - under low socio-economic conditions - produce deformity, mutilation, and in some patients blindness.

\section{(b) THE INFECTIOUS RESERVOIR}

The Fifth Expert committee on leprosy (World Health Organization, 1977a) considered that while multibacillary leprosy (BL to $\mathrm{LL}$ ) was likely to represent the major infectious reservoir, it was also considered that borderline tuberculoid and indeterminate patients in certain areas where the relative proportion of multibacillary leprosy is low, could play a non-negligible part in the transmission of leprosy. Since non-polar lepromatous leprosy patients (BL-LI) may revert immunologically, simply by antileprosy chemotherapy, it would seem likely that immunization at a pre-infection (and pre-clinical?) stage would have a significant effect on this population (I, BT-LI). This group of patients may well represent $50 \%$ or more of the infectious reservoir in a majority of endemic areas. Then remains the question whether or not vaccination could influence lack of resistance in subjects prone to develop polar lepromatous leprosy. If genetic factors should turn out to be of major importance for the development of their immunological defect, vaccination even at a pre-infection stage could be of little value. However, the data supporting the involvement of overriding genetic factors in this defect is in my view limited, e.g. the studies by Chakravartti and Vogel (1973) showed that the concordance for lepromatous leprosy in monozygous twins was not more than $50 \%$, a low figure, particularly in the light of the present views on the transmission of leprosy. Moreover, the nature of the defect in lepromatous leprosy, which will be discussed in more detail, indicates that the defect has features in common with so-called immunological tolerance. This type of immunological unresponsiveness can be restored by immunization with crossreactive antigens. For these reasons, it would seem likely that vaccination could have a significant impact on the infectious reservoir of leprosy.

\section{(E) Technical Considerations}

\section{(a) MECHANISMS INVOLVED IN HOST RESISTANCE TO INTRACELLULAR BACTERIA}

Immunity to intracellular bacteria is dependent on cell-mediated immune mechanisms rather than humoral antibodies (Mackaness and Blanden, 1967). 
Furthermore, studies in experimental animals have revealed that the carrier of this immunity is the thymus-dependent lymphocyte ( $\mathrm{T}$ cell) (Rees et al., 1967; Gaugas, 1968; Lane and Unanue, 1972; North, 1973). However, the T cell itself appears incapable of killing the parasites directly (Tripathy and Mackaness, 1969; MacGregor and Koster, 1971), but accomplishes this function through the mononuclear phagocyte (macrophage). At least two mechanisms seem to be involved:

(1) When encountering foreign antigens in the tissues, the $T$ cell may increase the antibacterial activity of the surrounding macrophages (Mackaness, 1971); this phenomenon has been called "macrophage activation" and may, at least in part, be accomplished through the release of molecular mediators (lymphokines) by stimulated T cells (Fowles et al., 1973; Godal et al., 1971).

(2) In addition, chemotactic substances (Bloom, 1971; David and David, 1972; Pick and Turk, 1972) are released which increase the influx of macrophage precursors (monocytes) into the lesion; this phenomenon has been called "macrophage mobilization" (World Health Organization, 1973; Mackaness, 1974).

While macrophage activation may represent an important defence mechanism against some infectious agents such as intracellular bacteria (World Health Organization, 1973), macrophage mobilization may be more important against others, such as viruses (Blanden, 1971). The possible contribution of bactericidal factors released by activated macrophages (Bast et al., 1974) has yet to be established.

In addition, macrophage/ $\mathrm{T}$ cell co-operation apparently takes place at the afferent level of the immune response to intracellular bacteria. This recognition of antigens from intracellularly growing bacteria by $T$ cells is restricted by I region genes of the major histocompatibility complex (Zinkernagel et al., 1977).

Experimentally, significant levels of cell-mediated immunity can be induced by live infection or by the help of adjuvants. Consequently, the two main possibilities for inducing cell-mediated immunity to $M$. leprae would appear to be (1) the use of an attenuated strain of $M$. leprae or closely-related live mycobacterium - or (2) non-viable antigens in an adjuvant.

Among these alternatives, an attenuated strain of $M$. leprae is unlikely to be produced before $M$. leprae can be cultivated on artificial media. This approach therefore appears to be unrealistic at present. The two other approaches are being pursued at present at various research centres.

With regard to a live cross-reactive mycobacterium, taxonomic studies on $M$. leprae, particularly by Dr Stanford's group in London, have indicated that $M$. leprae is more closely related to rapidly dividing mycobacteria, especially $M$. vaccae and $M$. non-chromogenicum, than to slowly growing mycobacteria (World Health Organization, 1977b). In the later studies, Stanford and his group have mainly used skin-reactivity in human populations with ultrasonicates of bacilli in their taxonomic studies. However, more information is needed on cell wall and surface antigens, since these may well be important in relation to protective immunity. Whether the cross-reactive strains are sufficiently safe to be used in viable form in man and also whether they would 
be capable of inducing cell-mediated immunity, remains unknown. If not, they may be considered for use as killed bacilli in an appropriate adjuvant. If a killed vaccine is to be used, it would seem more logical, at least at first sight, to use $M$. leprae itself. This has now become a realistic possibility because of the large number of organisms that can be harvested from armadillos, if these bacilli appear to contain the most important antigens for protective immunity. The potential of a killed vaccine depends on whether sufficiently strong and lasting cell-mediated immunity can be induced in man.

(b) SOME RECENT ADV ANCES MADE IN THE IMMLEP PROGRAMME TOWARDS THE DEVELOPMENT OF A VACCINE

The scientific plan for development of a vaccine was adopted by the 1 st Scientific Working Group in 1974 (World Health Organization, 1974)

The main steps were conceived as follows:

(1) Secure the supply of abundant $M$. leprae from infected armadillos.

(2) Develop methods for purifying $M$. leprae from tissues.

(3) To establish optimal methods for the killing of M. leprae.

(4) Antigenic and taxonomic relationship between $M$. leprae and other mycobacteria.

(5) Induction delayed type hypersensitivity to $M$. leprae

(a) in experimental animals

(b) in man.

(6) Induction of resistance to experimental infection.

IMMLEP has put great emphasis on the first point and will by 1978 have a "farm" of 250-300 animals reserved for M. leprae production. R. J. W. Rees at National Institute of Medical Research has taken responsibility for the IMMLEP "bank" and store, and distribution of $M$. leprae according to the directions of IMMLEP's Steering Committee. P. Draper, also at NIMR, rapidly developed a method based on a two-phase polymer system for purification of M. leprae (World Health Organization, 1977b). This method gave high purity and good yields, but the use of proteolytic enzymes raised the question if important antigens could be destroyed by the procedure. This question has not been entirely resolved, but recent investigations by P. Draper suggest that the method may be modified in such a way that bacilli of high purity can be produced without the use of proteolytic enzymes. By studies carried out by Shepard, Bloom, Lefford and Rees (World Health Organization, 1977b) M. leprae has been found to have two remarkable features which may turn out to be very advantageous in relation to a vaccine based on killed $M$. leprae. First, killed $M$. leprae without adjuvants can induce delayed type hypersensitivity in guinea pigs and mice and protect mice against experimental infection with $M$. leprae. Second, autoclaved $M$. leprae appear to be as good, or possibly better, both with regard to immunogenicity and protective immunity in mice.

With regard to taxonomy, as reported above, $M$. leprae seems to be more closely related to rapidly growing mycobacteria than to slowly growing mycobacteria, but a cultivable mycobacterial strain with an intimately close 
TABLE 3

Classification of T cells*†

\begin{tabular}{|c|c|c|c|c|c|c|c|c|c|}
\hline Cell & Symbol & Thy-1 & ALS & Ly-1 & Ly-2,3 & Ia $\neq$ & $\mathrm{FcR}$ & $\begin{array}{l}\text { Life } \\
\text { span }\end{array}$ & Special characteristics \\
\hline Initiator & $\mathrm{T}_{1}$ & High & $\mathrm{R} \S$ & + & + & + & $+?$ & Short & $\begin{array}{l}\text { Adheres to nylon wool. } \\
\text { Present in afferent lymph. } \\
\text { Absent from nodes. Binds } \\
\text { suppressive and enhancing } \\
\text { factors. }\end{array}$ \\
\hline B cell helper & $\mathrm{T}_{\mathrm{HB}}$ & Low & S & + & - & + & - & Long & $\begin{array}{l}\text { Low density. Becomes } \\
\text { Ala- } 1^{+} \text {if activated. }\end{array}$ \\
\hline $\mathrm{T}_{\mathrm{C}}$ cell helper $\ldots$ & $\mathrm{T}_{\mathrm{HC}}$ & Low & $S$ & + & $=$ & + & + & Long & \\
\hline Delayed hypersensitivity & $\mathrm{T}_{\mathrm{DHT}}$ & & & + & $=$ & $-?$ & & & \\
\hline Effector & & Low & $S$ & & & & & Long & Becomes Ala- $1^{+}, \mathrm{FcR}^{+}$if \\
\hline MHC allogeneic? & $\mathrm{T}_{\mathrm{C}}$ & & & - & + & & & & activated \\
\hline Non-MHC? & $\mathrm{T}_{\mathrm{E}}$ & & & + & + & + & & & \\
\hline Suppressor & $\mathrm{T}_{\mathrm{S}}$ & & & & & & & & High density. Abundant in \\
\hline Specific? & & & $S$ & - & + & $1-\mathrm{J}^{+}$ & & & spleen. \\
\hline Nonspecific? & & & & + & + & & & & \\
\hline
\end{tabular}

* This classification, especially the separation into $\mathrm{T}$ cell subdivision, is based on imperfect evidence. It should be regarded as tentative. See text for sources and details.

$\dagger$ From Snell (1978).

$\ddagger$ All $\mathrm{T}$ cells except the $\mathrm{T}_{\mathrm{DHT}}$ cell have been reported as carrying I a antigens. Ia antigens may ultimately be found on all $\mathrm{T}$ cells, and are likely to be different on each cell category (Murphy et al., 1977).

$\S \mathrm{R}=$ resistance; $\mathrm{S}=$ sensitive. 
relationship to $M$. leprae has yet to be discovered. However, based on skin-test data from various leprosy endemic areas, Stanford and his colleagues have come up with a new hypothesis with relevance to immunoprophylaxis in leprosy. They have found that sensitization to $M$. marianum is common in areas with high prevalence of leprosy and therefore suggest that certain environmental mycobacteria, such as $M$. marianum, may interfere with the induction of protective immunity induced by BCG or $M$. leprae itself.

Their hypothesis may explain several epidemiological findings, including the protective effect of BCG in children under the age of 4 in the Burma trial, but would seem to be in opposition to earlier studies in tuberculosis where atypical mycobacteria were found to give a partial protection against $M$. tuberculosis (Palmer and Long, 1966). Such a sensitization did not interfere with the protection provided by BCG in experimental animals, but would simulate such an effect in vaccine trials by reducing the differences between the vaccinated and the control group.

It would seem most important if Stanford et al. can substantiate their hypothesis by experimental studies. Thus, right now the most promising path appears to be the use of killed M. leprae.

However, one should bear in mind that these investigations to a large extent are based on delayed type hypersensitivity (DTH) investigations in mice and guinea pigs. The sensitivity of the growth of $M$. leprae in the mouse footpad to various immunological interventions, such as BCG and graft versus host reactions, limits its value as an assay for protective immunity.

These studies, therefore, raise the question of the relationship between DTH and protective immunity. Although Rees et al. (1967) more than 10 years ago showed that immunity to $M$. leprae was $\mathrm{T}$ cell dependent, more recent basic immunological research has been able to dissect the $\mathrm{T}$ cell compartment into functionally distinct sub-compartments (see Table 3), which raises the possibility that DTH and protective immunity is mediated through different $\mathrm{T}$ cells. My own biased view is that this is unlikely to be the case because the DTH reaction appears to me a most suitable device for dealing with intracellular parasites. Nevertheless, a note of caution should be made with regard to extrapolations from DTH reactions to protective immunity. The antigenic heterogeneity, only a few of which may be important for induction of protective immunity, underlines this reservation.

Studies in armadillos susceptible to disseminated leprosy may turn out to be most important. It is encouraging that Kirchheimer's group has reported protective effects with heat-killed $M$. leprae in Freund's complete adjuvant in this species (Kirchheimer et al., 1978).

In my view, the data obtained in the IMMLEP programme, so far, are sufficiently promising to make a start with the planning of a field trial. The first step in this endeavour is to ask what kind of epidemiological information is required to design a vaccine trial. Since a vaccine is unlikely to have any effect in subjects which have already converted immunologically to M. leprae, one such question is, at what age do such conversions take place?

The BCG trial in India has shown that a very large proportion of TB cases occurs in subjects tuberculin positive at the beginning of the trial (Guld, personal communication). Together with observations made in the British 
BCG trial (Hart and Sutherland, 1977) and epidemiological information about TB in industrialized countries, such as Norway, it suggests that reactivation is not an infrequent phenomenon in tuberculosis. What is the situation in leprosy? The age-related distribution of cases from Burma (Bechelli et al., 1973) may perhaps suggest that borderline leprosy occurs as result of "reactivation" or immunological deterioration from tuberculoid or sub-clinical leprosy. Information of this nature would seem necessary for determining the appropriate size of such a trial. How will chemotherapy affect the size?

Another question is how to secure a uniform classification of cases, especially indeterminate patients? Will a biopsy from all suspected cases be required?

These are only indications of the variety of important questions which have to be considered before a trial can be precisely designed. Obviously, several of them may require investigations in the field in order to be resolved. Thus, it would seem most important to start the planning now in order to avoid considerable delays when the experimental studies have been finished.

In fact, epidemiology would appear to be the area where more information is most needed for more precision in the future attacks on leprosy.

Ernest Fritchi once called the 1950's the decade for rehabilitation in leprosy, the sixties the decade for leprosy control and the seventies the decade for immunology. May I extend this and suggest that we make the 1980's the decade for epidemiology!

\section{Conclusions}

From what has been stated above, it is clear that there are many unanswered questions concerning both the development of an antileprosy vaccine and its potential use in leprosy control. Nevertheless, significant progress has been made over the last few years and now the possibility of using killed $M$. leprae appears most promising.

Many of the questions facing us in the coming years may only be answered by a field trial. This may for example be the only way of determining whether or not a vaccine can protect against lepromatous leprosy. Thus, such a trial may be viewed as an experiment to answer important scientific questions and not turned down a priori because of a prohibitive cost per dose of the vaccine to be tested. It has been estimated that $6-12$ years are required to fully evaluate the eff ect of a vaccine trial. I therefore sincerely hope that this year's Clayton Memorial Lecture does not nourish the misconception that an effective antileprosy vaccine will shortly be at hand.

The long time needed and the uncertainties in this area of research, as discussed above, require that other areas of leprosy research, such as chemotherapy, should be given top priority and proceed parallel to vaccinerelated research.

After all, leprosy is caused by a mycobacterium, and the best we can hope for is that leprosy research will provide a number of weapons such as new, inexpensive drugs, an effective vaccine and epidemiological tools, all of which may play their part in the fight against this crippling disease. 


\section{References}

Bast, R. C., Cleveland, R. P., Littman, B. H., Zbar, B. and Rapp, H. J. (1974). Acquired cellular immunity: extracellular killing of Listeria monocytogenes by a product of immunologically activated macrophages. Cell. Immunol. 10, 248.

Bechelli, L. M., Gallego Garbajosa, P., Gyi, Mg Mg, Uemura, K., Sundaresan, T., Tamondong, C., Martinez Dominguez, V. and Walter, J. (1973). Some epidemiological data on leprosy collected in a mass survey in Burma. Bull. Wld Hlth Org. 48, 335.

Blanden, R. V. (1971). Mechanisms of recovery from a generalized viral infection: mousepox. III. Regression of inf ectious foci. J. exp. Med. 133, 1090.

Bloom, B. R. (1971). In vitro approaches to the mechanism of cell-mediated immune reactions. Adv. Immunol. 13, 101.

Card, W. I. and Mooney, G. H. (1977). What is the monetary value of a human life? Br. med.J. $2,1627$.

Chakravartti, M. R. and Vogel, F. (1973). A twin study on leprosy. Top. hum. Gen. 1, 1.

David, J. R. and David, R. R. (1972). Prog. Allergy 23, 300.

Fowles, R. E., Fajardo, I. M., Leibowitch, J. L. and David, J. R. (1973). The enhancement of macrophage bacteriostasis by products of activated lymphocytes. J. exp. Med. 138, 952.

Gaugas, J. M. (1968). Enhancing effect of antilymphocytic globulin on human leprosy inf ection in thymectomized mice. Nature (London) 220, 1246.

Godal, T. (1974a). Immunological detection of sub-clinical infection in leprosy. Lepr. Rev. 45, 22.

Godal, T. (1974b). The role of immune responses to Mycobacterium leprae in host defence and tissue damage in leprosy. Prog. Immunol. II, 4, 161.

Godal, T. (1978). Prog. Allergy (In press).

Godal, T., Rees, R. J. W. and Lamvik, J. O. (1971). Lymphocyte mediated modification of blood-derived macrophage function in vitro: inhibition of growth of intra-cellular mycobacteria with lymphokines. Clin. exp. Immunol. 8, 625.

Hansen, G. Armauer and Looft, C. (1895). Leprosy: In its Clinical and Pathological Aspects. (John Wright \& Co., Bristol).

Hart, P. d'Arcy and Sutherland, I. (1977). BCG and vole bacillus vaccines in the prevention of tuberculosis in adolescence and early adult life. Final report to the Medical Research Council. Br. med.J. 2, 293.

Kirchheimer, W. F., Sanchez, R. M. and Shannon, E. J. (1978). Effect of specific vaccine on cell mediated immunity of armadillos against $M$. leprae. Leprosy Scientific Memoranda, Memo L-943/1.

Lane, F. C. and Unanue, E. R. (1972). Requirement of thymus (T) lymphocytes for resistance to listeriosis. J. exp. Med. 135, 1104.

Leprosy Review (1977). Symposium on dapsone resistance. Lepr. Rev. 48, no. 2.

MacGregor, D. D. and Koster, F. T. (1971). The mediator of cellular immunity. IV. Cooperation between lymphocytes and mononuclear phagocytes. Cell. Immunol. 2, 317.

Mackaness, G. B. (1971). Delayed hypersensitivity and the mechanism of cellular resistance to inf ection. Prog. Immunol. I, 413.

Mackaness, G. B. (1974). Immunity to intracellular parasites. Studies in vivo. Eth. med. J. 11, 175.

Mackaness, G. B. and Blanden, R. V. (1967). Prog. Allergy 11, 89.

North, R. (1973). Importance of thymus-derived lymphocytes in cell-mediated immunity to infection. Cell. Immunol. 7, 166.

Palmer, C. E. and Long, M. W. (1966). Effects of infection with atypical mycobacteria on BCG vaccination and tuberculosis. Am. Rev. resp. Dis. 94, 553.

Pick, E. and Turk, J. L. (1972). The biological activities of soluble lymphocyte products. Clin. exp. Immunol. 10, 1.

Rees, R. J. W., Waters, M. F. R., Weddell, A. G. M., and Palmer, E. (1967). Experimental lepromatous leprosy. Nature (London) 215, 599.

Sansarricq, H. and Walter, J. (1976). Position paper on leprosy. World Health Organization TDR/WP/76.16.

Shepard, C. C. (1971). The first decade in experimental leprosy. Bull. Wld Hlth Org. 44, 821. 
Snell, G. D. (1978). T cells, T cell recognition structures, and the major histocompatibility complex. Immunol. Rev. 38, 3.

Tripathy, S. P. and Mackaness, G. B. (1969). The effect of cytotoxic agents on the passive transfer of cell-mediated immunity. J. exp. Med. 130, 17.

Waters, M. F. R., Rees, R. J. W., Pearson, J. M. H., Laing, A. B. G., Helmy, H. S., and Gelber, R. H. (1978). Rifampicin for lepromatous leprosy: nine years' experience. Br. med.J. 1, 133.

World Health Organization (1973). Cell-mediated immunity and resistance to infection. Bull. Wld Hlth Org. Tech. Rep. Ser. no. 519.

World Health Organization (1974). Report of the First Meeting of IMMLEP Project Group.*

World Health Organization (1977a). WHO Expert Committee on Leprosy. Bull Wld Hlth Org. Tech. Rep. Ser. no. 607.

World Health Organization (1977b). Report of the Third IMMLEP Scientific Working Group Meeting.*

Zinkernagel, R. M., Althage, A., Adler, B., Blanden, R. V., Davidson, W. F., Kees, U., Dunlop, M. B. C. and Shreffler, D. C. (1977). H-2 restriction of cell-mediated immunity to an intracellular bacterium. Effector $\mathrm{T}$ cells are specific for Listeria antigen in association with H-21 region-coded self-markers J. exp. Med. 145, 1353.

*Available on request to World Health Organization. 